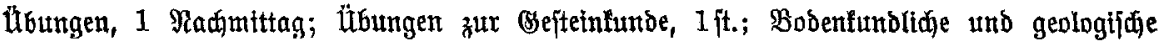

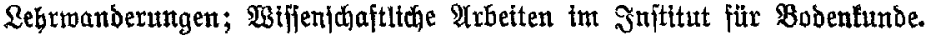

\title{
Fadidmiffenidunften:
}

a) Forftithe:

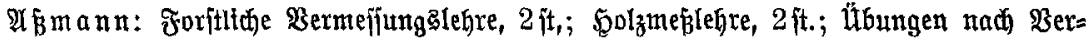

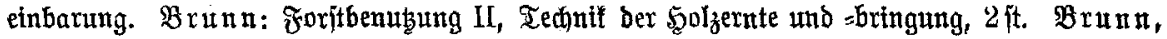

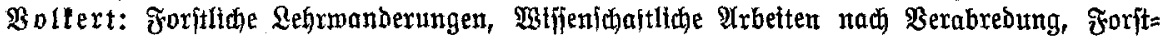

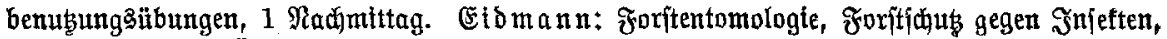

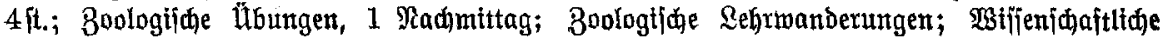

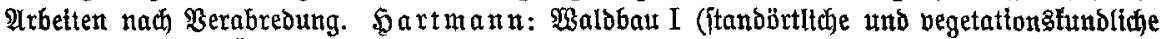

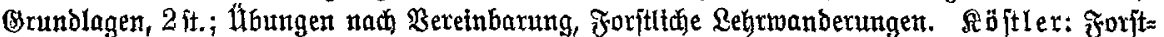

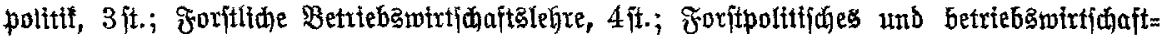

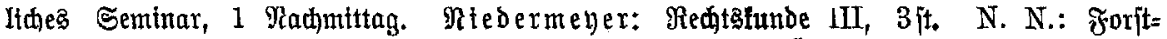

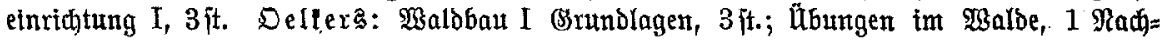

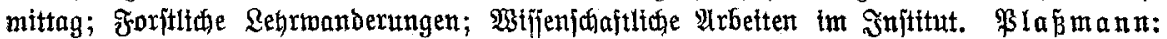

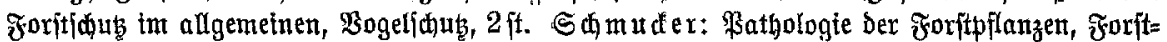

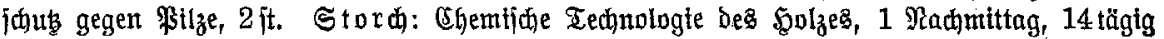

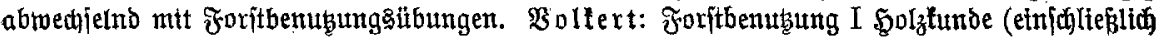

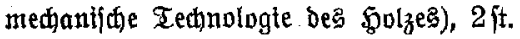

b) Sonftige:

Sertng: Naturidup, I it. Sowark: Findereimirtidaft I Grumblagen, 1 ft. Delfers:

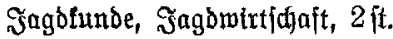

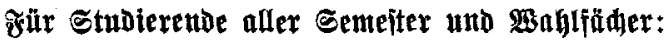

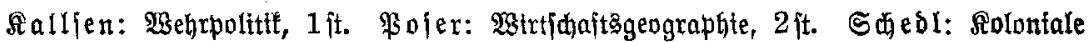
Forjtentomologie, 1 ft. N. N.: Englij内, 2 jt. Retbesübungen 1 Radjmittag.

Die Borlejungen Geginnen am Mittmod, dem 2. Rowentber 1938. Einjhreibung: Dienștag, Den 11. Dltober Gta Sounabend, den 12. November 1938. Atumeldungen fdrift=

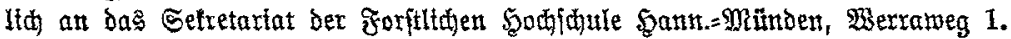

\section{Alfademifdie Ladartiht.}

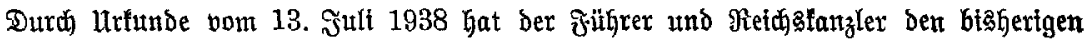

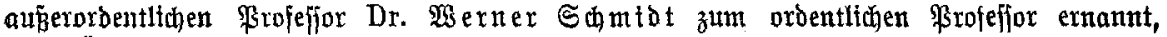

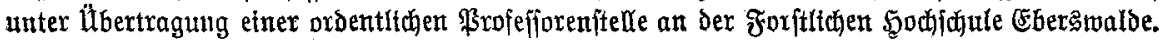

\section{Codesnađhrihten.}

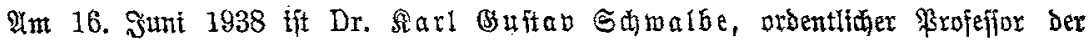

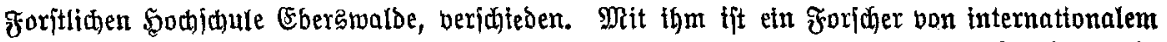

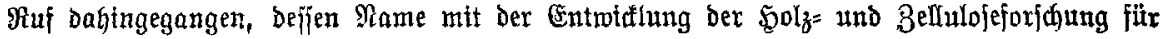
tmmer verfinupft fein wird.

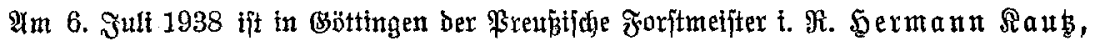

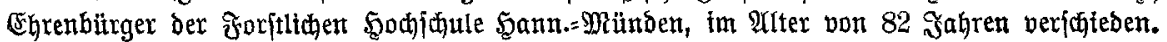

\section{Drudfehlerverbefferung.}

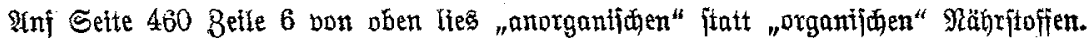

